\title{
Immunohistochemical detection of ZAP-70 in 341 cases of non-Hodgkin and Hodgkin lymphoma
}

\author{
Joan H Admirand, George Z Rassidakis, Lynne V Abruzzo, Jose R Valbuena, Dan Jones
} and L Jeffrey Medeiros

Department of Hematopathology, University of Texas MD Anderson Cancer Center, Houston, TX, USA

\begin{abstract}
Using immunohistochemical methods, we evaluated zeta-associated protein (ZAP)-70 expression in 341 cases of non-Hodgkin and Hodgkin lymphoma. In B-cell NHL, ZAP-70 was positive in five of six (83\%) precursor B-lymphoblastic lymphoma, 11 of 37 (30\%) chronic lymphocytic leukemia/small lymphocytic lymphoma (CLL/ SLL), five of $39(13 \%)$ mantle cell lymphoma, one of $12(8 \%)$ Burkitt lymphoma, and one of 12 (8\%) nodal marginal zone B-cell lymphoma. In 22 cases of CLL/SLL, seven of nine $(78 \%)$ with unmutated IgV $\mathrm{V}_{\mathrm{H}} \mathrm{genes}$ expressed ZAP-70, compared with one of $13(8 \%)$ with mutated $\lg V_{H}$ genes $(P=0.0015$ Fisher's exact test). ZAP70 expression was not detected in diffuse large B-cell lymphoma $(n=26)$, extranodal marginal zone B-cell lymphoma of mucosa-associated lymphoid tissue $(n=24)$, follicular lymphoma $(n=21)$, plasma cell myeloma/ plasmacytoma $(n=10)$, lymphoplasmacytic lymphoma $(n=10)$, or splenic marginal zone lymphoma $(n=6)$. In T/NK-cell NHL, ZAP-70 was positive in all extranodal natural killer (NK)/T-cell lymphoma, nasal-type $(n=6)$ and enteropathy-type T-cell lymphoma $(n=4)$, four of five $(80 \%)$ subcutaneous panniculitis-like T-cell lymphoma, six of eight $(75 \%)$ mycosis fungoides, three of five $(60 \%)$ precursor T-lymphoblastic lymphoma, 10 of 17 (59\%) peripheral T-cell lymphoma, two of four (50\%) blastic NK-cell lymphoma, one of three (33\%) T-cell prolymphocytic leukemia, 13 of 52 (25\%) anaplastic large cell lymphoma, and one of six (17\%) angioimmunoblastic T-cell Iymphoma. Seven of 12 (58\%) cutaneous CD30-positive lymphoproliferative disorders were also ZAP-70-positive. In Hodgkin Iymphoma, ZAP-70 was negative in neoplastic cells in all cases tested. ZAP-70 staining in B-cell lymphomas and reactive $\mathrm{T}$ cells was predominantly nuclear with variable cytoplasmic staining. By contrast, ZAP-70 staining in T/NK-cell lymphomas was heterogeneous, and a shift from predominantly nuclear to predominantly cytoplasmic staining was observed, particularly in those neoplasms with high-grade morphology. In summary, ZAP-70 is expressed by many lymphoma types, correlates with immunoglobulin heavy-chain variable region gene mutational status in CLL/SLL, and can be detected reliably using immunohistochemical methods.
\end{abstract}

Modern Pathology (2004) 17, 954-961, advance online publication, 7 May 2004; doi:10.1038/modpathol.3800145

Keywords: ZAP-70; immunohistochemistry; chronic lymphocytic leukemia/small lymphocytic lymphoma; nonHodgkin lymphoma; Hodgkin lymphoma

Zeta-associated protein (ZAP)-70, a member of the Syk family of tyrosine kinases, plays an important role in T-cell receptor signaling, natural killer (NK) cell activation and early B-cell development. ${ }^{1}$ ZAP70 is not normally expressed in mature B cells. However, ZAP-70 is expressed in a subset of cases of chronic lymphocytic leukemia/small lymphocytic lymphoma (CLL/SLL) with unmutated immunoglobulin heavy-chain variable region $\left(\operatorname{IgV}_{\mathrm{H}}\right)$ genes and

Correspondence: Dr L Jeffrey Medeiros, MD, Department of Hematopathology, Box 72, University of Texas MD Anderson Cancer Center, 1515 Holcombe Blvd, Houston, TX 77030, USA. E-mail: jmedeiro@mdanderson.org

Received 6 February 2004; revised 18 March 2004; accepted 23 March 2004; published online 7 May 2004 is associated with poor clinical outcome. ${ }^{2-4}$ Few reports have examined ZAP-70 protein expression by immunohistochemical methods in CLL/SLL, and ZAP-70 expression patterns in other types of nonHodgkin and Hodgkin lymphoma has not been defined.

The physiological role of ZAP-70 is best understood in the context of normal T-cell receptor function and immunity. Activation of the T-cell receptor occurs when the receptor is engaged by antigen in the appropriate context, resulting in sequential phosphorylation/activation of a cascade of protein tyrosine kinases. The proximal signaling events involve the Src protein tyrosine kinases that phosphorylate immunoreceptor tyrosine-based activation motifs (ITAMS) on the cytoplasmic domains 
of CD3 and the zeta chain components of the T-cell receptor. Phosphorylated ITAMS provide docking sites for the Syk protein tyrosine kinases (ZAP-70 and Syk). Subsequent phosphorylation of ZAP-70 triggers downstream signaling events that culminate in transcriptional induction of genes that regulate cell function, proliferation and death. ${ }^{5,6}$ Similar proximal events including phosphorylation of ITAMS on the immunoglobulin $\alpha / \beta$ dimer by Src protein tyrosine kinases, and subsequent activation of Syk protein tyrosine kinases have been implicated in the B cell receptor signaling pathway. Mature B cells, however, generally lack ZAP-70 and use the related protein tyrosine kinase, Syk. ${ }^{5}$

Recent investigations suggest that ZAP-70 is expressed in early B-cell development and plays a role in the transition of pro-B to pre-B-cell lymphocytes. ${ }^{1}$ Additional studies demonstrated increased tyrosine phosphorylated proteins and association of ZAP-70 with IgM and CD79b after ligation of the Bcell receptor in ZAP-70-positive CLL/SLL. ${ }^{4}$ These studies suggest that the role of ZAP-70 is not restricted to B-cell receptor signaling, and may enhance other signaling mechanisms in a subset of CLL/SLL.

In this study, we used immunohistochemical techniques and routinely fixed, paraffin-embedded tissue to survey ZAP-70 expression in 341 cases of non-Hodgkin and Hodgkin lymphoma. In addition, we sequenced the $\operatorname{IgV}_{\mathrm{H}}$ gene in 22 of the CLL/SLL cases to determine if ZAP-70 expression, detected by immunohistochemical methods, predicts $\operatorname{IgV}_{\mathrm{H}}$ gene mutational status.

\section{Materials and methods}

\section{Case Selection}

The study group included a total of 325 cases of nonHodgkin lymphoma and 16 cases of Hodgkin lymphoma accessioned between 1985 and 2003 at The University of Texas MD Anderson Cancer Center. Each case was classified according to the World Health Organization classification of lymphoid neoplasms. ${ }^{7}$ The diagnoses for all cases were established on the basis of morphology and appropriate immunophenotypic and/or molecular data.

We evaluated whole-tissue sections or tissue microarraays. The latter included duplicate, triplicate or quadruplet tumor cores from 50 cases of anaplastic large-cell lymphoma and 30 cases of mantle cell lymphoma. A manual tissue arrayer (Beecher Instruments, Silver Springs, MD, USA) was used to construct the tissue microarrays as described previously. $^{8}$

\section{Immunohistochemistry}

Immunohistochemical studies were performed using routinely fixed and processed, paraffin- embedded sections of whole-tissue or tissue microarrays and heat-induced epitope retrieval as described previously. ${ }^{9}$ The ZAP-70 monoclonal antibody (Upstate Cell Signaling Systems, Lake Placid, NY, USA) was incubated at $4^{\circ} \mathrm{C}$ for $5-7 \mathrm{~h}$. Detection of primary antibody was achieved using the LSAB + kit (DAKO, Carpinteria, CA, USA), which contains secondary biotinylated antibody and streptavidin/horseradish peroxidase complex, according to the manufacturer's recommendations. The chromogen was $3,3^{\prime}$-diaminobenzidine $/ \mathrm{H}_{2} \mathrm{O}_{2}$ (DAKO) and slides were counterstained with hematoxylin.

\section{Scoring of Positive Cells}

Tissues were scored in evenly labeled areas. All cases were scored independently by at least two of the authors. Nuclear staining of non-neoplastic, reactive $\mathrm{T}$ cells served as an internal control in each case. Neoplasms demonstrating nuclear staining in greater than $20 \%$ of tumor cells, regardless of intensity or the degree of concurrent cytoplasmic staining were considered positive.

\section{Determination of $\operatorname{IgV}_{H}$ Mutational Status}

The methods used to detect $\operatorname{IgV}_{\mathrm{H}}$ somatic hypermutation in 22 CLL/SLL cases have been previously described. ${ }^{10}$ Briefly, mononuclear cells were isolated from whole blood by centrifugation over a Ficoll gradient. CD19-positive cells were isolated using anti-CD19-conjugated immunomagnetic beads (Mitenyi Biotec, Auburn, CA, USA). The purity of the isolate, evaluated by flow cytometry, was determined to be 95-98\% CD19 + cells. Total RNA was extracted from the isolate and the RNA quality was assessed by agarose gel electrophoresis. Total RNA was reverse transcribed using oligo-d(T) primer and the First-Strand cDNA Synthesis kit (Amersham Parmacia Biotech). The cDNA was amplified using a mixture of six $5^{\prime} \mathrm{V}_{\mathrm{H}}$ leader primers which amplify all $\mathrm{V}_{\mathrm{H}}$ families, together with a $3^{\prime}$ constant region primer $(\mathrm{Cu})$. In cases that failed to amplify, a mixture of $\mathrm{V}_{\mathrm{H}}$ framework 1 primers (V BASE database; http:// www.mrc-cpe.cam.ac.uk/PRIMERS.php?menu+901) was used and two independent PCR amplification reactions were performed for each sample. Amplified products were separated by agarose gel electrophoresis and products were sequenced. The degree of somatic hypermutation was determined by aligning the sequence of the products with germline sequences listed in the V BASE database (http:// www.mrc-cpe.cam.ac.uk/ALIGNMENTS.php?menu $=901$ ) using the DNA plot program available on the internet (http://www.mrc-cpe.cam.ac.uk/DNAPLOT. php?menu =901).

The $\operatorname{IgV}_{\mathrm{H}}$ gene mutation status of each case of CLL/SLL was designated as unmutated if there were $2 \%$ or fewer mutations compared with the germline 
$\mathrm{V}_{\mathrm{H}}$ gene sequence. ${ }^{11}$ Cases with greater than $2 \%$ variation from the $V_{H}$ germline sequence were designated as mutated.

\section{Cell Lines}

Nine lymphoma cell lines were evaluated for ZAP-70 expression by Western blot analysis. The five non-Hodgkin lymphoma cell lines included two derived from anaplastic large-cell lymphoma, Karpas 299 (a gift from Dr M Kadin, Boston, MA, USA) and SU-DHL-1 (from DSMZ, Braunschweig, Germany); Jurkat cell lysate (acute lymphoblastic leukemia) provided by the ZAP-70 manufacturer; a mantle cell lymphoma, Mino, ${ }^{12}$ and a diffuse large B-cell lymphoma, SKI-DLBCL-1. ${ }^{13}$ The four Hodgkin lymphoma cell lines used were HD-MyZ, ${ }^{14} \mathrm{HD}-$ LM2, ${ }^{15}$ L-428, ${ }^{16}$ and KM-H2 (DSMZ). ${ }^{17}$ Cell lines were maintained in RPMI 1640 medium supplemented with $1 \%$ nonessential amino acids, $10 \%$ fetal calf serum (Life Technologies Inc.), and 1\% streptomycin-penicillin. Cell cultures were incubated at $37^{\circ} \mathrm{C}$ in a humidified atmosphere containing $5 \% \mathrm{CO}_{2}$.

\section{Protein Extraction and Western Blot Analysis}

Cell lines in log-phase growth were collected, washed twice in cold phosphate-buffered saline (PBS) and lysed at $4^{\circ} \mathrm{C}$ in lysis buffer composed of $25 \mathrm{mM}$ HEPES, pH 7.7, $400 \mathrm{mM} \mathrm{NaCl}, 0.5 \%$ Triton $\mathrm{X}-100,1.5 \mathrm{mM} \mathrm{MgCl}_{2}, 2 \mathrm{mM}$ EDTA, $2 \mathrm{mM}$ DTT, $0.1 \mathrm{mM}$ PMSF, the protease inhibitors leupeptin $10 \mu \mathrm{g} / \mathrm{ml}$, peptstatin $2 \mu \mathrm{g} / \mathrm{ml}$, antipain $50 \mu \mathrm{g} / \mathrm{ml}$, aprotinin $2 \mu \mathrm{g} / \mathrm{ml}$, chymostatin $20 \mu \mathrm{g} / \mathrm{ml}$, and benzamidine $2 \mu \mathrm{g} / \mathrm{ml}$, and the phosphatase inhibitors $2 \mathrm{mM} \mathrm{NaF}, 1 \mathrm{mM} \mathrm{Na} \mathrm{VO}_{4}$, and $20 \mathrm{mM} \beta$-glycerophosphate. Aliquots of cell lysates (70 $\mu \mathrm{g}$ protein) were resolved in 10\% SDS-PAGE, transferred to nitrocellulose polyvinylidene difluoride (PVDF) membranes and probed with monoclonal ZAP-70 antibody (Upstate Cell Signaling Systems, Lake Placid, NY, USA). Reactions were visualized with secondary antibody conjugated with horseradish peroxidase (BioRad, Hercules, CA, USA) using enhanced chemiluminescence reagents (Amersham Pharmacia, Piscataway, NJ, USA). Polyclonal $\beta$-actin antibodies (Sigma, St Louis, MO, USA) served as an internal positive control for all cell lines.

\section{Results}

\section{Sequence Analysis of the $\operatorname{IgV}_{H}$ Genes}

Direct sequence analysis of the PCR products in 22 CLL/SLL cases demonstrated that nine had unmutated $\operatorname{IgV}_{\mathrm{H}}$ genes and the remaining 13 cases had mutated $\mathrm{IgV}_{\mathrm{H}}$ genes (Table 2). VH family usage in these neoplasms is listed in Table 2. The majority of CLL/SLLs used the VH3 (13 of 22) or VH4 (four of 22) families. Two of nine (22\%) unmutated cases used VH3-21, while no cases of mutated $\operatorname{IgV}_{\mathrm{H}}$ CLL/ SLL used VH3-21.

\section{Western Blot Analysis}

The specificity of the ZAP-70 antibody was confirmed by detection of a $70 \mathrm{kDa}$ protein in several cell lines (Figure 2). Detection of $\beta$-actin expression served as an internal control. Strong ZAP-70 expression was detected in two T-cell lymphoma cell lines: Jurkat cell lysate and Karpas 299. Strong ZAP-70 expression was also detected in HD-LM-2, an atypical Hodgkin lymphoma cell line of T-cell lineage. A low level of ZAP-70 was expressed in Mino, a mantle cell lymphoma cell line. No significant ZAP-70 expression was detected in five cell lines tested including HD-MyZ, L-428, KM-H2, SU-DHL-1 and SKI-DLBCL-1.

\section{ZAP-70 in Benign Lymphoid Tissues}

In benign lymph nodes, nuclear ZAP-70 staining was seen in paracortical $\mathrm{T}$ lymphocytes and rare, scattered, small lymphocytes in the mantle zones and follicle centers. Histiocytes demonstrate coarse, granular cytoplasmic staining with ZAP-70. This staining may not be specific and was not considered positive in this study.

\section{ZAP-70 in B-Cell Non-Hodgkin Lymphomas}

ZAP-70 expression in non-Hodgkin lymphomas is summarized in Table 1. ZAP-70 was detected in 23 of 203 (11\%) of B-cell neoplasms, including 11 of $37(30 \%)$ CLL/SLL, five of six (83\%) precursor B-lymphoblastic leukemia/lymphoma, five of 39 (13\%) mantle cell lymphoma, one of 12 (8\%) Burkitt lymphoma, and one of $12(8 \%)$ nodal marginal zone B-cell lymphoma.

ZAP-70 expression compared with $\mathrm{IgV}_{\mathrm{H}}$ mutational status in CLL/SLL is summarized in Table 2. ZAP-70 was detected in eight of 22 cases, including seven of nine $(78 \%)$ with unmutated $\operatorname{IgV}_{\mathrm{H}}$ genes and one of $13(8 \%)$ with mutated $\operatorname{IgV}_{\mathrm{H}}$ genes $(P=0.0015$; Fisher's exact test). In all, 14 of the cases with known mutational status were evaluated for ZAP-70 in both bone marrow biopsy sections and clot sections. Generally, more intense nuclear staining was observed in the clot sections compared with the corresponding bone marrow biopsy sections, although the biopsy specimen was sufficient in 12 of 14 cases. Two cases had equivocal staining of tumor cells in the bone marrow biopsy specimens that were resolved by examination the corresponding clot sections. One case of interfollicular CLL/ SLL, which demonstrated no ZAP-70 expression in tumor cells, showed intense expression in $\mathrm{T}$ cells within follicles undergoing regression. Intensely staining $\mathrm{T}$ cells in regressing follicles, compared to 
interfollicular $\mathrm{T}$ cells, were also observed in other cases of non-Hodgkin and Hodgkin lymphoma.

ZAP-70 expression was detected in five of six (83\%) precursor B-lymphoblastic leukemia/lymphoma. Positive cases showed uniform, predominantly nuclear staining. ZAP-70 expression was detected in five of $39(13 \%)$ cases of mantle cell lymphoma. Unlike the predominantly nuclear and variable cytoplasmic staining of tumor cells seen in other ZAP-70-positive B-cell lymphomas, ZAP-70-positive mantle cell lymphomas generally had weak, variable nuclear staining (Figure 1e). However, one case of blastoid mantle cell lymphoma showed strong, uniform nuclear staining similar to that detected in ZAP-70-positive CLL/SLL. Strong, uniform, predominantly nuclear ZAP-70 staining was also detected in one of five cases of Burkitt lymphoma and in one of 12 cases of nodal marginal zone B-cell lymphoma (Figure 1d).

ZAP-70 expression was not detected in the remaining B-cell neoplasms assessed including diffuse large B-cell lymphoma $(n=26)$, follicular lymphoma $(n=21)$, extranodal marginal zone lymphoma $(n=12)$, lymphoplasmacytic lymphoma/ Waldenström macroglobulinemia $(n=10)$, plasma cell myeloma/plasmacytoma $(n=10)$ or splenic marginal zone lymphoma $(n=6)$. The diffuse large B-cell lymphoma group included two cases of Richter's transformation in patients with a confirmed history of CLL/SLL.
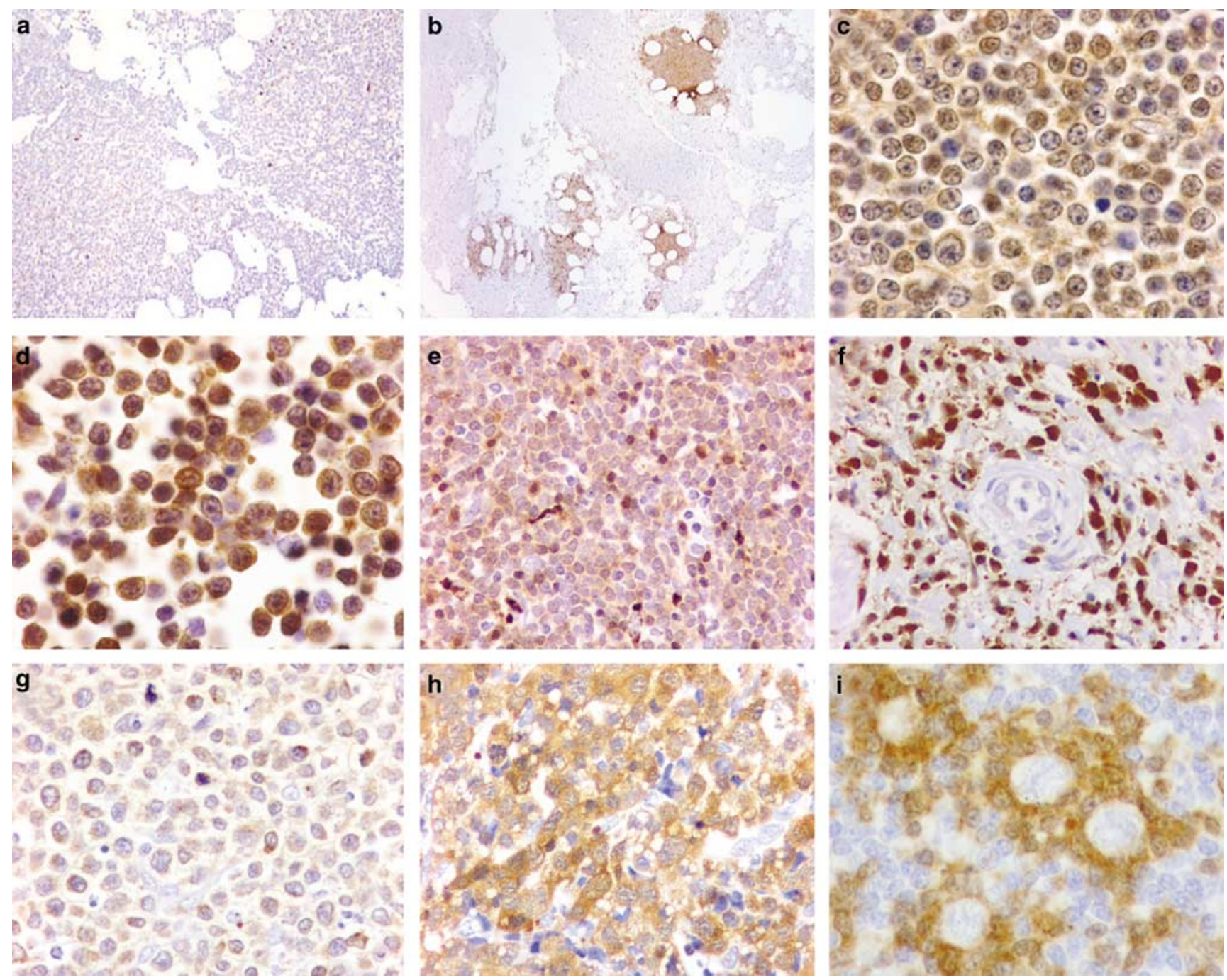

Figure 1 ZAP-70 expression in non-Hodgkin and Hodgkin lymphomas. (a) Bone marrow biopsy involved by ZAP-70-negative CLL/SLL. Scattered ZAP-70-positive benign T cells are present. (b) Bone marrow clot section involved by ZAP-70-positive CLL/SLL. (c) Nuclear and cytoplasmic ZAP-70 staining of CLL/SLL in lymph node. (d) Strong nuclear and cytoplasmic ZAP-70 staining in a case of nodal marginal zone B-cell lymphoma. (e) Weak nuclear and cytoplasmic ZAP-70 staining in a case of mantle cell lymphoma. Note the weak staining intensity compared to small, admixed brightly staining T cells. (f) Strong nuclear and cytoplasmic ZAP-70 staining in a case of extranodal NK/T-cell lymphoma, nasal-type. (g) Strong cytoplasmic and weak to absent nuclear ZAP-70 staining in a case of enteropathytype T-cell lymphoma. (h) Strong cytoplasmic and weak nuclear ZAP-70 staining in a case of ALK-negative anaplastic large-cell lymphoma. (i) Lack of ZAP-70 immunoreactivity in L\&H cells of nodular lymphocyte predominant Hodgkin lymphoma. Note the brightly staining $\mathrm{T}$ cells encircling tumor cells. 


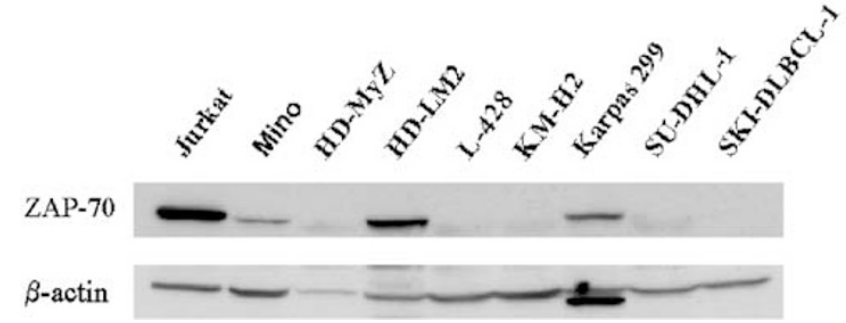

Figure 2 Western blot analysis of cell lines. Specificity of the anti-ZAP-70 antibody was confirmed by detection of a $70 \mathrm{kDa}$ protein in lysates from several cell lines. Strong ZAP-70 expression was detected in Jurkat, a T-cell lymphoma line, Karpas 299, an ALK-positive anaplastic large-cell lymphoma cell line of T-cell lineage and HDLM2, an atypical CD2-positive, CD4-positive Hodgkin lymphoma cell line. A low level of ZAP-70 was expressed in Mino, a mantle cell lymphoma cell line. No significant ZAP-70 expression was detected in HD-MyZ, L-428, KMH2, SU-DHL-1, or SKI-DLBCL. $\beta$-actin expression served as a control for protein load and integrity.

\section{ZAP-70 in T/NK-Cell Non-Hodgkin Lymphomas}

ZAP-70 expression was detected in 49 of 112 (44\%) T-cell lymphomas including all cases of enteropathy type T-cell lymphoma $(n=4)$, four of five $(80 \%)$ subcutaneous panniculitis-like T-cell lymphoma, six of eight $(75 \%)$ mycosis fungoides, three of five (60\%) precursor T-lymphoblastic leukemia/lymphoma, 10 of 17 (59\%) peripheral T-cell lymphoma, unspecified, one of three (33\%) T-cell prolymphocytic leukemia, 13 of $52(25 \%)$ anaplastic large cell lymphoma, and one of six (17\%) angioimmunoblastic T-cell lymphoma. We also assessed 12 cutaneous CD30-positive lymphoproliferative disorders including seven cases of cutaneous anaplastic large cell lymphoma and five cases of lymphomatoid papulosis. ZAP-70 was positive in four $(57 \%)$ and three $(60 \%)$ cases, respectively. In anaplastic large cell lymphoma, ZAP-70 was more often positive in the ALK-negative $(11 / 27 ; 41 \%)$ neoplasms compared with ALK-positive $(2 / 25 ; 8 \%)$ neoplasms $(P=0.012$; Fisher's exact test). Unlike the expression patterns we observed in most B-cell neoplasms and within reactive T cells, ZAP-70 staining in T/NK-cell neoplasms was heterogeneous and a shift from predominantly nuclear to predominantly cytoplasmic staining was observed, particularly in those neoplasms with high grade morphology (Figure 1g, h).

We also assessed ZAP-70 in a small number of neoplasms presumed to be of NK-cell origin. Strong, uniform cytoplasmic and nuclear staining for ZAP70 was seen in all six cases of NK/T-cell lymphoma, nasal-type (Figure 1f) and in two of four blastic NKcell lymphoma. The latter group of tumors, however, may originate from type 2 dendritic (DC2) cells, also known as plasmacytoid monocytes. ${ }^{18}$

\section{ZAP-70 in Hodgkin Lymphomas}

None of the neoplastic cells in the cases of classical Hodgkin or nodular lymphocyte predominant
Table 1 ZAP-70 expression in 341 cases non-Hodgkin and Hodgkin lymphoma

\begin{tabular}{|c|c|}
\hline Subtype & $\begin{array}{l}\text { Positive cases/ } \\
\text { Total number }\end{array}$ \\
\hline Precursor lymphoblastic leukemia/lymphoma & $8 / 11$ \\
\hline Precursor B & $5 / 6$ \\
\hline Precursor T & $3 / 5$ \\
\hline \multicolumn{2}{|l|}{ Mature B-cell neoplasms } \\
\hline $\begin{array}{l}\text { Chronic lymphocytic leukemia/small } \\
\text { lymphocytic lymphoma }\end{array}$ & $11 / 37$ \\
\hline IgH mutated & $1 / 13$ \\
\hline IgH unmutated & $7 / 9$ \\
\hline IgH not assessed & $3 / 15$ \\
\hline Lymphoplasmacytic lymphoma & $\mathbf{0} / \mathbf{1 0}$ \\
\hline Marginal zone B-cell lymphoma & $1 / 42$ \\
\hline Splenic marginal zone lymphoma & $0 / 6$ \\
\hline Extranodal marginal zone B-cell lymphoma & $0 / 24$ \\
\hline Nodal marginal zone B-cell lymphoma & $1 / 12$ \\
\hline Plasma cell myeloma/plasmacytoma & $\mathbf{0} / \mathbf{1 0}$ \\
\hline Follicular lymphoma & $\mathbf{0} / \mathbf{2 1}$ \\
\hline Grade I & $0 / 5$ \\
\hline Grade II & $0 / 8$ \\
\hline Grade III & $0 / 8$ \\
\hline Mantle cell lymphoma & $5 / 39$ \\
\hline Burkitt lymphoma/leukemia & $1 / 12$ \\
\hline Diffuse large B-cell lymphoma & $\mathbf{0} / \mathbf{2 6}$ \\
\hline \multicolumn{2}{|l|}{ Mature T-cell and NK-cell neoplasms } \\
\hline Extranodal NK/T-cell lymphoma, nasal type & $6 / 6$ \\
\hline Mycosis fungoides/Sezary syndrome & $6 / 8$ \\
\hline Mycosis fungoides, patch or plaque stage & $3 / 5$ \\
\hline $\begin{array}{l}\text { Mycosis fungoides transformation to } \\
\text { large cell lymphoma }\end{array}$ & $3 / 3$ \\
\hline $\begin{array}{l}\text { Primary cutaneous CD30-positive T-cell } \\
\text { lymphoproliferative disorders }\end{array}$ & $7 / 12$ \\
\hline $\begin{array}{l}\text { Primary cutaneous anaplastic large cell } \\
\text { lymphoma }\end{array}$ & $4 / 7$ \\
\hline Lymphomatoid papulosis & $3 / 5$ \\
\hline Angioimmunoblastic T-cell lymphoma & $1 / 6$ \\
\hline Peripheral T-cell lymphoma, unspecified & $10 / 17$ \\
\hline Anaplastic large cell lymphoma & $13 / 52$ \\
\hline Anaplastic large-cell lymphoma ALK-positive & $2 / 25$ \\
\hline Anaplastic large-cell lymphoma ALK-negative & $11 / 27$ \\
\hline Miscellaneous T-cell lymphomas & $11 / 16$ \\
\hline T-cell prolymphocytic leukemia & $1 / 3$ \\
\hline Enteropathy-type T-cell lymphoma & $4 / 4$ \\
\hline $\begin{array}{l}\text { Subcutaneous panniculitis-like T-cell } \\
\text { lymphoma }\end{array}$ & $4 / 5$ \\
\hline Blastic NK-cell lymphoma & $2 / 4$ \\
\hline Hodgkin lymphoma & $\mathbf{0} / 16$ \\
\hline Nodular lymphocyte predominant & $0 / 4$ \\
\hline Nodular sclerosis & $0 / 4$ \\
\hline Mixed cellularity & $0 / 7$ \\
\hline Lymphocyte-depleted & $0 / 1$ \\
\hline
\end{tabular}

Bold values indicate the total of each subtype.

Hodgkin lymphoma were positive for ZAP-70. Bright nuclear and cytoplasmic staining was observed in T cells surrounding the neoplastic cells in nodular lymphocyte predominant Hodgkin lymphoma (Figure 1i). Increased numbers of bright ZAP-70-positive $\mathrm{T}$ cells were also seen within nodules in nodular lymphocyte predominant Hodgkin lymphoma, similar to staining patterns described for CD57 in this disease. ${ }^{19}$ 
Table 2 Comparison of ZAP-70 expression with IgH variable gene sequences in CLL/SLL

\begin{tabular}{lclll}
\hline CLL Patient & Gender & IgH status $^{\mathrm{a}}$ & VH Family & ZAP-70 \\
\hline CLL1 & $\mathrm{M}$ & Mutated & VH4-39 & Negative \\
CLL2 & $\mathrm{M}$ & Mutated & VH3-07 & Negative \\
CLL3 & $\mathrm{F}$ & Mutated & VH1-02 & Negative \\
CLL4 & $\mathrm{F}$ & Mutated & VH3-34 & Negative \\
CLL5 & $\mathrm{F}$ & Mutated & VH4-34 & Negative \\
CLL6 & $\mathrm{F}$ & Mutated & VH2-05 & Negative \\
CLL7 & $\mathrm{M}$ & Mutated & VH3-11 & Negative \\
CLL8 & $\mathrm{F}$ & Mutated & VH3-07 & Negative \\
CLL9 & $\mathrm{M}$ & Mutated & VH4-34 & Negative \\
CLL10 & $\mathrm{M}$ & Mutated & VH3-43 & Negative \\
CLL11 & $\mathrm{M}$ & Mutated & VH3-48 & Negative \\
CLL12 & $\mathrm{M}$ & Mutated & VH3-15 & Positive \\
CLL13 & $\mathrm{M}$ & Mutated & VH3-07 & Negative \\
CLL14 & $\mathrm{M}$ & Unmutated & VH3-21 & Positive \\
CLL15 & $\mathrm{F}$ & Unmutated & VH3-53 & Negative \\
CLL16 & $\mathrm{F}$ & Unmutated & VH3-23 & Positive \\
CLL17 & $\mathrm{F}$ & Unmutated & VH3-21 & Positive \\
CLL18 & $\mathrm{M}$ & Unmutated & VH1-58 & Negative \\
CLL19 & $\mathrm{M}$ & Unmutated & VH5-51 & Positive \\
CLL20 & $\mathrm{F}$ & Unmutated & VH4-39 & Positive \\
CLL21 & $\mathrm{F}$ & Unmutated & VH1-18 & Positive \\
CLL22 & $\mathrm{M}$ & Unmutated & VH3-30 & Positive \\
& & &
\end{tabular}

${ }^{\mathrm{a}}$ Unmutated IgH variable genes defined as $\leq 2 \%$ variation compared to the germline sequence.

\section{Discussion}

The role of ZAP-70 in T-cell receptor signaling is well established. Although ZAP-70 expression was previously thought to be limited to T and NK cells, recent evidence suggests that ZAP-70 may play a role in early B-cell development. In addition, ZAP70 expression in CLL/SLL cases has received much attention in the literature, as ZAP-70 correlates with the absence of somatic hypermutations in their immunoglobulin variable region $(\mathrm{IgV})$ genes. ${ }^{1,2,4} \mathrm{In}$ this study, we used immunohistochemical techniques applied to routinely fixed, paraffin-embedded tissue sections to evaluate ZAP-70 expression in 341 cases of non-Hodgkin and Hodgkin lymphoma. In addition, we sequenced IgH variable gene regions in 22 CLL/SLL cases to evaluate if ZAP-70, assessed by immunohistochemical methods, could predict IgH variable gene status.

ZAP-70 expression was evaluated in a variety of B-cell lymphomas with proposed cellular origins that span the spectrum of B-cell differentiation. Expression of ZAP-70 in five of six cases of precursor B-lymphoblastic leukemia/lymphoma is interesting in light of its proposed role in the pro- to pre-B-cell stage of differentiation in normal B cells. ${ }^{1}$ Our studies suggest primitive signaling pathways that utilize ZAP-70 may be maintained when B cells are transformed at early stages of development.

We also detected ZAP-70 expression in approximately $30 \%$ of CLL/SLL cases. Our studies support a good correlation between ZAP-70 expression and unmutated $\mathrm{IgH}$ variable genes in CLL/SLL and demonstrate detection by immunohistochemical methods on routinely fixed, paraffin-embedded tissue sections is a specific (92\%) and relatively sensitive $(78 \%)$ marker of unmutated $\mathrm{IgH}$ variable genes. In recent studies, increased ZAP-70 mRNA has been demonstrated in a subset of CLL/SLL cases lacking somatic hypermutation in their IgV genes. ${ }^{2-4}$ Somatic hypermutation of the Ig genes is a diversification mechanism activated in $B$ cells at the germinal center stage of differentiation. ${ }^{20}$ Since somatic hypermutation is a hallmark of B cells which have passed through the germinal center, some investigators have postulated that CLL/SLL associated with unmutated $\mathrm{IgV}$ genes is derived from naïve, pre germinal B cells and that CLL/SLL with mutated IgV genes is derived from post germinal B cells. ${ }^{11,21-23}$ Since patients with unmutated $\operatorname{IgV}$ genes are reported to have a significantly worse prognosis, ${ }^{11}$ reliable and easier methods to differentiate these groups at early stages of disease would be clinically valuable. ZAP-70 assessment in routinely processed tissue, in our experience, is a convenient alternative to sequencing.

Mantle cell lymphoma is also considered to be primarily derived from pre-germinal center B cells with absent or low levels of somatic hypermutation. $^{24,25}$ In our studies, however, ZAP-70 was detected in only $13 \%$ mantle cell lymphoma cases. We also detected low level ZAP-70 protein expression in Mino, a mantle cell lymphoma cell line. If ZAP-70 expression in CLL/SLL is a consequence of transformation of a naïve $B$ cell, we would have anticipated that other B-cell neoplasms of proposed pre-germinal center cell origin, such as mantle cell lymphoma, would express ZAP-70. In abstract form, one group has detected ZAP-70 in $40 \%$ of mantle cell lymphoma. ${ }^{26}$ However, other groups, also in abstract form, report results similar to our own. ${ }^{27,28}$ The reasons for the discrepancy between the preliminary results of Bano et al..$^{26}$ compared with others are unknown. We would also not have anticipated ZAP-70 expression in one case of nodal marginal zone B-cell lymphoma and in one case of Burkitt lymphoma, as these neoplasms are believed to be of post germinal center cell origin, with somatic hypermutation IgV gene occurring in nearly all cases. ${ }^{29-32}$ On the other hand, the majority of Bcell non-Hodgkin lymphomas of proposed postgerminal center cell origin were negative for ZAP-70.

Alternatively, it has been suggested that ZAP-70 expression and absence of somatic hypermutation are a consequence of aberrant T-cell-independent Bcell receptor signaling mechanisms. The lack of ZAP-70 expression in the majority of mantle cell lymphomas and lack of ZAP-70 in two of our unmutated $\operatorname{IgV}_{\mathrm{H}}$ CLL/SLL cases, however, suggest that ZAP-70 is not a necessary effector in T-cellindependent B-cell receptor signaling, nor is it necessary to block somatic hypermutation.

The majority of low-grade T-cell neoplasms expressed ZAP-70 and showed strong nuclear and 
variable cytoplasmic staining. A minority of higher morphologic grade or large-cell T-cell neoplasms expressed ZAP-70 and positive cases demonstrated a shift from predominantly nuclear to predominantly cytoplasmic with variable nuclear staining. The heterogeneous ZAP-70 staining patterns of Tcell neoplasms, especially in higher histologic grade tumors, may be attributable to loss of the normal T-cell receptor signaling repertoire. ZAP-70 was only expressed in the minority of anaplastic largecell lymphomas; however, ZAP-70 expression was significantly more common $(P=0.012$; Fisher's exact test) in ALK-negative anaplastic large-cell lymphoma. Since ZAP-70 is expressed with variable intensities in all normal T cells, absence of ZAP-70 may be diagnostically useful in paraffin sections as another marker of an aberrant T-cell immunophenotype suggesting malignant lymphoma.

In nodular lymphocyte predominant Hodgkin lymphoma, intensely ZAP-70-positive T lymphocytes were numerous in tumor nodules, and often surrounded neoplastic cells (satelliting) analogous to CD57-positive T cells. ${ }^{19}$ Similar intensely staining $\mathrm{T}$ lymphocytes were occasionally observed in regressing follicles. These findings are consistent with an activated T-cell phenotype which would likely include increased ZAP-70 expression because of its crucial role in T-cell receptor signaling growth pathways.

In summary, we assessed a variety of non-Hodgkin and Hodgkin lymphomas for ZAP-70 expression. In B-cell lymphomas, ZAP-70 was commonly expressed in precursor B-lymphoblastic leukemia/ lymphoma and in CLL/SLL, and rarely in mantle cell lymphoma, Burkitt lymphoma, and nodal marginal zone B-cell lymphoma. We found a good correlation between ZAP-70 positivity and $\operatorname{IgV}_{\mathrm{H}}$ mutation status in CLL/SLL. In T-cell lymphomas, most neoplasms composed of smaller cells demonstrated ZAP-70 expression. By contrast, ZAP-70 was expressed only in a minority of large cell T-cell lymphomas, such as anaplastic large-cell lymphoma, and correlated with ALK-negativity in this group. In NK-cell neoplasms, ZAP-70 expression was common and intensely positive in extranodal NK/T-cell lymphoma of nasal-type.

\section{References}

1 Schweighoffer E, Vanes L, Mathiot A, et al. Unexpected requirement for ZAP-70 in pre-B cell development and allelic exclusion. Immunity 2003;18: 523-533.

2 Crespo M, Bosch F, Villamor $\mathrm{N}$, et al. ZAP-70 expression as a surrogate for immunoglobulin-variable-region mutations in chronic lymphocytic leukemia. N Engl J Med 2003;348:1764-1775 (see comment).

3 Wiestner A, Rosenwald A, Barry TS, et al. ZAP-70 expression identifies a chronic lymphocytic leukemia subtype with unmutated immunoglobulin genes, in- ferior clinical outcome, and distinct gene expression profile. Blood 2003;101:4944-4951.

4 Chen L, Widhopf G, Huynh L, et al. Expression of ZAP70 is associated with increased B-cell receptor signaling in chronic lymphocytic leukemia. Blood 2002; 100:4609-4614.

5 Kong G, Dalton M, Wardenburg JB, et al. Distinct tyrosine phosphorylation sites in ZAP-70 mediate activation and negative regulation of antigen receptor function. Mol Cell Biol 1996;16:5026-5035.

6 Ashe JM, Wiest DL, Abe R, et al. ZAP-70 protein promotes tyrosine phosphorylation of $\mathrm{T}$ cell receptor signaling motifs (ITAMs) in immature CD4(+)8(+) thymocytes with limiting p56(lck). J Exp Med 1999; 189:1163-1168.

7 Jaffe ES, Harris NL, Stein H, (eds). World Health Organization Classification of Tumours. Pathology and Genetics of Tumors of Haematopoietic and Lymphoid Tissues. IARC Press: Lyon, 2001.

8 Rassidakis GZ, Jones D, Thomaides A, et al. Apoptotic rate in peripheral T-cell lymphomas. A study using a tissue microarray with validation on full tissue sections. Am J Clin Pathol 2002;118:328-334.

9 Khoury JD, Medeiros LJ, Rassidakis GZ, et al. Differential expression and clinical significance of tyrosinephosphorylated STAT3 in ALK+ and ALK- anaplastic large cell lymphoma. Clin Cancer Res 2003;9: 3692-3699.

10 McCarthy H, Weirda WG, Barron LL, et al. High expression of activation-induced cytidine deaminase (AID) and splice variants is a distinctive feature of poor-prognosis chronic lymphocytic leukemia. Blood 2003;101:4903-4908.

11 Hamblin TJ, Davis Z, Gardiner A, et al. Unmutated Ig V(H) genes are associated with a more aggressive form of chronic lymphocytic leukemia. Blood 1999;94: 1848-1854.

12 Lai R, McDonnell TJ, O’Connor SL, et al. Establishment and characterization of a new mantle cell lymphoma cell line, Mino. Leuk Res 2002;26:849-855.

13 Goy A, Gilles F, Remache Y, et al. Establishment of a human cell line (SKI-DLCL-1) with a t(1;14)(q21;q32) translocation from the ascites of a patient with diffuse large cell lymphoma. Leukemia Lymphoma 2001; 40: 419-442.

14 Diehl V, Pfreundschuh M, Fonatsch C, et al. Phenotypic and genotypic analysis of Hodgkin's disease derived cell lines: histopathological and clinical implications. Cancer Surv 1985;4:399-419.

15 Drexler HG, Leber BF, Norton J, et al. Genotypes and immunophenotypes of Hodgkin's disease-derived cell lines. Leukemia 1988;2:371-376.

16 Diehl V, Kirchner HH, Schaadt M, et al. Hodgkin's disease: establishment and characterization of four in vitro cell lines. J Can Res Clin Oncol 1981;101:111-124.

17 Kamesaki H, Fukuhara S, Tatsumi E, et al. Cytochemical, immunologic, chromosomal, and molecular genetic analysis of a novel cell line derived from Hodgkin's disease. Blood 1986;68:285-292.

18 Herling M, Teitell MA, Shen RR, et al. TCL1 expression in plasmacytoid dendritic cells (DC2s) and the related CD4+ CD56+ blastic tumors of skin. Blood 2003;101:5007-5009.

19 Nguyen PL, Ferry JA, Harris NL. Progressive transformation of germinal centers and nodular lymphocyte predominance Hodgkin's disease: a comparative immunohistochemical study. Am J Surg Pathol 1999; 23:27-33. 
20 Tonegawa S. Somatic generation of antibody diversity. Nature 1983;302:575-581.

21 Rosenwald A, Alizadeh AA, Widhopf G, et al. Relation of gene expression phenotype to immunoglobulin mutation genotype in B cell chronic lymphocytic leukemia. J Exp Med 2001;194:1639-1647.

22 Gurrieri C, McGuire P, Zan H, et al. Chronic lymphocytic leukemia B cells can undergo somatic hypermutation and intraclonal immunoglobulin $\mathrm{V}(\mathrm{H}) \mathrm{DJ}(\mathrm{H})$ gene diversification. J Exp Med 2002;196:629-639.

23 Dunn-Walters D, Thiede C, Alpen B, et al. Somatic hypermutation and B-cell lymphoma. Philos Trans R Soc Lond Biol Sci 2001;356:73-82.

24 Kienle D, Krober A, Katzenberger T, et al. VH mutation status and VDJ rearrangement structure in mantle cell lymphoma: correlation with genomic aberrations, clinical characteristics, and outcome. Blood 2003;102: 3003-3009.

25 Camacho FI, Algara P, Rodriguez A, et al. Molecular heterogeneity in MCL defined by the use of specific $\mathrm{VH}$ genes and the frequency of somatic mutations. Blood 2003;101:4042-4046.

26 Bano A, Amin H, Olatonade D, et al. ZAP-70 expression in mantle cell lymphomas. Mod Pathol 2004; 17(suppl 1):239A (abstract).
27 Barry TS, Hwang HC, Bacchi CE, et al. ZAP-70 expression in B- and T-cell lymphoma: An immunohistochemical study of 266 cases. Mod Pathol 2004;17(suppl 1):240A (abstract).

28 Sup SJ, Steinle R, Zhao X, et al. Zap-70 expression in B-cell hematologic malignancy is not limited to CLL/ SLL. Mod Pathol 2004;17(suppl 1):272A (abstract).

29 Hallas C, Greiner A, Peters K, et al. Immunoglobulin $\mathrm{VH}$ genes of high-grade mucosa-associated lymphoid tissue lymphomas show a high load of somatic mutations and evidence of antigen-dependent affinity maturation. Lab Invest 1998;78:277-287.

30 Nakamura N, Kuze T, Hashimoto Y, et al. Analysis of the immunoglobulin heavy chain gene variable region of 101 cases of peripheral B cell neoplasms and B cell chronic lymphocytic leukemia in the Japanese population. Pathol Int 1999;49:595-600.

31 Tamaru J, Hummel M, Marafioti T, et al. Burkitt's lymphomas express VH genes with a moderate number of antigen-selected somatic mutations. Am J Pathol 1995;147:1398-1407.

32 Klein U, Klein G, Ehlin-Henriksson B, et al. Burkitt's lymphoma is a malignancy of mature B cells expressing somatically mutated $\mathrm{V}$ region genes. Mol Med 1995;1:495-505. 